offer virtually no security-which in essence is what the care of so many itinerant and disturbed psychotics demands. Until such time as the interim Butler Committee recommendations ${ }^{8}$ are implemented and more secure units are made available this practice will continue and very likely increase.

What stands out in the report is the degree to which the prison medical service takes care-and takes good care-of substantial numbers of society's sore thumbs-alcoholics, difficult epileptics, drug-addicts, psychopaths, and psychotics, particularly chronic schizophrenics. In this respect prisons take second place only to mental hospitals. Indeed, what seems an obvious step to take is to pool the resources of these two vital if unglamorous services. Happily there is evidence that this symbiosis is already beginning and is a two-way process. Several prison M.O.s with psychiatric qualifications and experience are now undertaking sessional work in the National Health Service clinics in London, Winchester, Cardiff, and on the Isle of Wight. Conversely, the number of visiting psychotherapists to the prisons rose from 50 in 1971 to 60 in 1973, most of whom are consultant psychiatrists in the National Health Service. Furthermore, there is a slow but steady increase in the appointment of joint consultants in forensic psychiatry who divide their time between the Prison Service and the National Health Service or university departments. The next logical step forward is to pool not only personnel but premises.

\footnotetext{
${ }^{3}$ Home Office, Report on the work of the Prison Department, 1973, Cmnd. 5767. London, H.M.S.O., 1974.

2 British Medical fournal, 1967, 1, 317

3 British Medical fournal, 1969, 3, 426.

4 British Medical fournal, 1970, 3, 537.

British Medical fournal, 1970, 3, 537.

British Medical fournal, 1971, 3, 443

British Medical fournal, 1972, 4, 129

8 British Medical fournal, 1973, 4, 438. Report of the Committee on Mentally Abnormal Offenders, Cmnd. 5698. London, H.M.S.O., 1974.
}

\section{Health Education in the Reorganized N.H.S.}

Our failure to make any real impact on the epidemic of cigarette-induced disease in nearly 25 years has been partly due to lack of resources devoted to health education but also to the isolation of the public health services responsible for health education from the main medical services in hospital and general practice. The reorganization of the N.H.S. has made it possible to extend health education and, perhaps, begin to control the great modern epidemic diseases. If this opportunity is to be grasped there are three main needs. Clinicians and all other health service staff have to be convinced that health education could be effective in the prevention of disease. Secondly, training will be needed: training of health education officers to take charge of district health education units, training of specialists in health education and specialists in epidemiology, training of health service staff, especially clinical doctors and nurses, in the part that they should play in health education, and the training of future staff by including health education in the basic training of medical students and other health professions. Finally, there will have to be adequate resources in both materials and staffing.

The D.H.S.S. acted with commendable speed in giving advice $^{1}$ to area health authorities on health education in March 1974. Regrettably, little action followed this initiative, because salary scales for health education officers have not yet been decided by the Whitley Council, and in the absence of agreement the Department of Health has not permitted area health authorities to appoint such staff. Furthermore, a recent D.H.S.S. staff training memorandum ${ }^{2}$ has shown that there have been fewer applications than expected for places on the various training courses provided (at D.H.S.S. expense) for health education officers and other health service staff. Apparently area health authorities have not taken advantage of the chance offered to train staff so badly needed in this field.

In these times of financial stringency it is all too easy to postpone action, especially as most of the ex-public-health doctors with experience in health education are now overburdened with administrative problems in their new roles in the reorganized N.H.S. The present neglect of health education is not unique; other branches of preventive medicine are suffering equally for similar reasons. Has not the time perhaps come for the D.H.S.S. to correct the flight from the field in preventive medicine which the reorganization of the N.H.S. has caused ? Experienced staff at present sitting at their desks in the Department, the regions, and the areas, are needed to provide the skilled manpower for preventive medicine in the districts.

${ }^{1}$ National Health Service, Reorganization of National Health Service and of Local Government, HRC (74) 27. London, Department of Health and Social Security, 1974.

2 Department of Health and Social Security, Staff Training Memorandum, STM (74) 37. London, D.H.S.S., 1974.

\section{Treatment for Cataplexy}

Cataplexy is part of the syndrome of idiopathic narcolepsy and manifests itself as a brief attack of muscular weakness. (The term should be distinguished from catalepsy, which refers to the maintenance of unnatural postures.)

The cataplectic attack is nearly always a response to sudden emotion, most often laughter or anger, less often elation, sexual excitement, or fear; and it is always the same one or two emotions that are characteristic for any particular patient. The attack may affect the whole body, with collapse on to the floor, or at other times involve only a sagging of the jaw or trembling and slight buckling of the knees. It usually has a duration of seconds but in rare cases may last for several minutes. The narcoleptic's spells of irresistable sleep usually precede the first cataplectic attack by some years.

When the normal person falls asleep he spends the first hour in non-rapid eye movement (N.R.E.M., orthodox, or E.E.G. slow-wave) sleep. A pathognomonic feature of idiopathic narcolepsy is the frequent and immediate passage from wakefulness into rapid eye movement (R.E.M. or paradoxical) sleep. ${ }^{1}$ The latter state includes a profound loss of muscle tone ${ }^{2}$ and abolition of the $\mathrm{H}$-reflex ${ }^{3}$ (the knee-jerk elicited by direct electrical stimulation of the tibial nerve). Cataplexy is, therefore, today regarded as a partial manifestation of R.E.M. sleep: indeed the patient may slip into R.E.M. sleep during his cataplectic attack, as Guilleminault et al.4 have recently reported. Some of the tricyclic drugs prevent the appearance of R.E.M. sleep, and among these the most powerful is clomipramine, ${ }^{5}$ which has proved particularly successful in the prevention of cataplexy. ${ }^{6}$

Most narcoleptic patients find the spells of daytime sleep to be their greater problem, but there are some in whom cataplectic attacks recur several times a day and so constitute a major disability. Guilleminault et al. selected five patients 
with numerous cataplectic attacks and subjected them to prolonged monitoring of daytime E.E.G., eye movements, muscle tone, and H-reflex. They confirmed the loss of tone and of H-reflex in the cataplectic attack, and in one man whose attacks were especially numerous they tried out the effect of a variety of chemical agents during 36-hour recordings. Atropine injections had no effect on cataplexy, and levodopa was little better; L-hydroxytryptophan made the attacks more frequent, but clomipramine was dramatically successful in abolishing cataplexy when given intravenously for an individual attack or when given prophylactically by mouth in a dose of $75 \mathrm{mg}$ daily. Unfortunately clomipramine does little to diminish the sleep attacks, but where cataplexy is the greater problem an effective treatment is now available.

\footnotetext{
1 Rechtschaffen, A., et al., Electroencephalography and Clinical Neurophysio$\log y, 1963,15,599$.

Berger, R. J., 1961, Science, 134, 840

3 Hodes, R., and Dement, W., Electroencephalography and Clinical Neuro-

physiology, 1964, 17, 617. $\log y, 1974,31,255$.

5 Dunleavy, D. L. F., et al., British fournal of Psychiatry, 1972, 120, 663.

6 Passouant, P., Baldy-Moulinier, M., and Aussilloux, C., Revue Neurologique, $1970,123,56$
}

\section{Safe Manipulation of Microbial Genes}

Last summer we reported ${ }^{1}$ and discussed the call ${ }^{2}$ of the United States National Academy of Sciences for a voluntary worldwide moratorium on certain types of genetic experiments with micro-organisms. The potential benefits and potential hazards of techniques which allow the experimental manipulation of the genetic composition of micro-organisms has now been assessed by a working party of distinguished scientists under Lord Ashby, which with commendable speed has produced an excellent, clear report ${ }^{3}$ intended to stimulate discussion in the scientific community and by the general public. Unanimously, the working party concluded that the potential benefits of such experiments are likely to be very great and that, with rigorous safeguards, the potential hazards can be eliminated, contained, or at any rate so reduced as to be extremely rare.

The necessary safeguards depend on many familiar precautions and on some others that are both novel and ingenious. Many scientists already engage in potentially hazardous research using radioactive materials, unstable chemicals, or pathogenic microbes. Their safety depends to a large extent on their training and their familiarity with the material with which they work. In microbiology to-day, however, there are some newcomers to the scene whose laboratory experience does not include the disciplines familiar to those accustomed to handling pathogens. For many such newcomers-geneticists, molecular biologists, and biochemists, for exampleguidance may be necessary; and a sensible code of practice should be made available. This would include the precautions already accepted as routine in public health laboratories. ${ }^{4}$ If special risks are attached to particular experiments, especially if large-scale work is concerned, the precautions have to be much more painstaking than the familiar routine. Fortunately, detailed advice is available $;^{5}$ and the working party's report properly lays emphasis on the importance of safeguarding the public and the environment as well as the scientists themselves. Besides the normal precautions to ensure containment other safeguards are described. There should be systematic long-term epidemiological monitoring of the health of those engaged on genetic experiments with microbes; a biological safety officer should be named for each laboratory; and a central advisory service should be available. This might well lead to certain categories of genetic experiments being done, if at all, only under very special and rigid safeguards. There are also suggestions about some ingenious genetical devices for "disarming" the organisms used in genetic experiments and for testing the usefulness of some microbes which have not yet found such favour as the famous Escherichia coli, especially K12. Strains of E.coli should be investigated thoroughly to improve our knowledge of their viability in the human intestine and their capacity to transfer plasmids to strains of the organism resident there.

Against the potential hazards, none of which should cause alarm to any well-trained medical microbiologist, great potential benefits are evident. A deeper understanding of gene action is likely to be reached far more quickly by microbiological manipulations than by any other current techniques. This could lead to the discovery of how the genes which cause certain kinds of cancer actually promote the growth of tumours. The study of plasmids and their transmission has already advanced our understanding of bacterial virulence and drug resistance; and there may well be other benefits to come in the understanding and control of microbial infections. Another possible benefit is the prospect that one might isolate, and then very rapidly multiply, the genes responsible for promoting the synthesis of, for example, insulin, or pituitary growth hormone, or human antibodies, or human interferon, or microbial proteins for vaccine production.

In agriculture, too, the potential benefits are of worldwide significance. In Britain, for example, nearly one-third of the energy cost of raising a field of wheat is attributable to energy required to manufacture nitrogen fertilizers. If genes which code for nitrogen fixation could be introduced and made to function in non-leguminous crops such as cereals, the benefits would be immense to a world which is short of food partly because of the high cost of artificial manures and the expenditure of energy in making them. Admittedly this thinking contains an element of speculation, but it rests on informed judgement. In short, nobody should doubt the range and value of the potential benefits or be deterred from seeking them. The hazards also are only potential; and we have the means of controlling them if we have also the will.

\footnotetext{
1 British Medical fournal, 1974, 3, 483.

2 Nature, 1974, 250, 175.

3 Report of a Working Party on the Experimental Manipulation of the Genetic Composition of Micro-organisms. London, H.M.S.O., 1975. Cmnd 5880, price $26 \mathrm{p}$.

${ }^{4}$ Public Health Laboratory Service, Monograph Series No. 6. London, H.M.S.O., 1974.

${ }^{5}$ Harris-Smith, R., and Evans, C. E. T., Bioengineering and protection during hazardous microbiological processes. Biotechnology and Bioengineering Symposium no 4. New York and Chichester, John Wiley and Sons, 1974
} 